\title{
ESTRATÉGIAS PARA ENSINAR ESPORTE NAS AULAS DE EDUCAÇÃO FÍSICA: um estudo na cidade de Aparecida/SP
}

\author{
José Martins Freire Júnior? \\ Daniel Teixeira Maldonado² \\ Sheila Aparecida Pereira dos Santos Silva ${ }^{3}$
}

\section{RESUMO}

O objetivo desse estudo foi descrever e analisar as estratégias e estilos de ensino que professores de EF que atuam na cidade de Aparecida-SP afirmam utilizar para ensinar os conteúdos esportivos para turmas do $6^{\circ}$ ao $9^{\circ}$ ano do Ensino Fundamental. Trata-se de uma pesquisa qualitativa, de orientação fenomenológica, que utilizou uma pergunta desencadeadora para provocar os discursos dos professores pesquisados. A análise ocorreu em nível individual (análise ideográfica) e, posteriormente, abrangeu o grupo como um todo (análise nomotética). Os resultados mostraram que a maioria dos docentes utilizam os jogos pré-desportivos, o jogo formal com regras oficiais, exercícios de repetição dos fundamentos e atividades lúdicas para ensinar os conteúdos esportivos. Os estilos de ensino comando e tarefa são os mais comumente utilizados. A maior parte dos discursos evidenciou que os professores utilizam estratégias de reprodução para ensinar os conteúdos relacionados ao esporte.

Palavras-chave: Educação Física. Estratégias de Ensino. Esporte Escolar.

1 Mestre em Educação Física. Universidade São Judas Tadeu (USJT). São Paulo/São Paulo, Brasil.

E-mail: jmf.juninho@hotmail.com

2 Doutor em Educação Física. Universidade São Judas Tadeu (USJT). São Paulo/São Paulo, Brasil.

E-mail: danieltmaldonado@yahoo.com.br

3 Doutora em Educação. Professora da Universidade São Judas Tadeu (USJT). São Paulo//São Paulo, Brasil.

E-mail: sheila.silva@uol.com.br 
STRATEGIES FOR TEACHING SPORTS IN CLASSES OF PHYSICAL EDUCATION CLASSES: a study in the city of Aparecida/SP

\begin{abstract}
The objective of this study was to describe and analyze the strategies and teaching styles that EF teachers who work in the city of Aparecida-SP claim to use to teach the sports contents for grades 6 through 9 of Elementary School. It is a qualitative research, with a phenomenological orientation, that used a triggering question to provoke the discourses of the researched teachers. The analysis took place at the individual level (ideographic analysis) and later covered the group as a whole (nomothetic analysis). The results showed that most teachers use pre-sports games, formal game with official rules, repetition exercises of fundamentals and playful activities to teach sports content. The command and task teaching styles are the most commonly used. Most of the speeches showed that teachers use strategies of reproduction to teach content related to sports.
\end{abstract}

Keywords: Physical Education. Teaching Strategies. School Sport.

\title{
ESTRATEGIAS PARA LA ENSEÑANZA DE LOS DEPORTES EN CLASES DE EDUCACIÓN FÍSICA: un estudio en la ciudad de Aparecida/SP
}

\section{RESUMEN}

El objetivo de este estudio fue describir y analizar las estrategias y estilos de enseñanza que diez profesores de Educación Física de la ciudad de Aparecida, que trabajan en ocho escuelas municipales dicen utilizan para enseñar contenidos deportivos para las clases de $6^{\circ}$ a $9^{\circ}$ grado de la enseñanza básica. Se trata de una investigación cualitativa de orientación fenomenológica, que utiliza una pregunta estimuladora del discurso de las personas investigadas. El análisis se llevó a cabo en un nivel individual (análisis ideográfico) y posteriormente cubierto el grupo en su conjunto (análisis momotética). Los resultados mostraron que la mayoría de los maestros usan juegos pre-deportivos, el juego formal con las normas oficiales, la repetición de ejercicios, y las actividades lúdicas para enseñar contenidos deportivos. Los estilos de enseñanza del Comando y de la Tarea son los más comúnmente utilizados. La mayor parte de los discursos mostraron que los maestros utilizan estrategias reproductivas para la enseñanza de contenidos relacionados con el deporte.

Palabras clave: Educación Física. Estrategias de Enseñanza. Deporte Escolar. 


\section{INTRODUÇÃO}

A Educação Física (EF) tem buscado, ao longo dos anos, avançar e superar os modelos dominantes da área, principalmente aqueles relacionados com o ensino das modalidades esportivas mais convencionais que adotam uma metodologia de ensino com enfoque tecnicista. O cotidiano escolar ainda é composto por práticas esportivas que produzem fortemente estes modelos (CORREIA, 2006).

Percebe-se a presença de tais modelos nas aulas de EF escolar, quando os profissionais dão ênfase às técnicas esportivas. Os alunos são ensinados por meio de exercícios que buscam aprimorar a técnica necessária para tais práticas. No entanto, vale lembrar que o indivíduo é um ser sociocultural e as aulas restritas à técnica esportiva, por enfatizarem apenas aspectos motores, colaboram para a desintegração desses aspectos em relação aos cognitivos e afetivo-sociais que deveriam estar em sintonia na formação dos discentes.

Segundo análise de Guimarães et. al. (2001), nessa proposta de ensino, alguns aspectos importantes não são desenvolvidos, como: respeito mútuo, a cooperação e a afetividade, que são a base para se viver em sociedade.

O esporte, todavia, é um conteúdo ensinado com muita frequência nas aulas de EF escolar, o que nos fez levantar questões a respeito de como este ensino vem ocorrendo.

Será que o esporte tem sido utilizado como um veículo para desenvolver o raciocínio crítico, a autonomia e a responsabilidade dos alunos?

Será que nas aulas, cujo conteúdo é o esporte, são dadas oportunidades aos estudantes para refletirem sobre o que fazem, para proporem modificações e para criarem a partir do material oferecido pelos professores, ou mesmo proporem atividades que contem com elementos esportivos e que sejam totalmente novas?

Os professores, por sua vez, conhecem diferentes formas de ensinar que compartilhem decisões relativas ao planejamento, desenvolvimento das aulas e avaliação com seus alunos?

Pensamos que um ponto primordial a ser pesquisado é a percepção que o próprio professor possui sobre sua maneira de ensinar. Se ele não percebe diferentes possibilidades didáticas, como poderia dominar estratégias de ensino que visam ao desenvolvimento dos mais diferentes aspectos e dimensões na formação dos estudantes?

Diante desse leque de questões didático-pedagógicas, o objetivo desse estudo foi descrever e analisar as estratégias e estilos de ensino que professores de EF que atuam na cidade de Aparecida-SP afirmam utilizar para ensinar os conteúdos esportivos para turmas do $6^{\circ}$ ao $9^{\circ}$ ano do Ensino Fundamental.

\section{MÉTODO}

Este estudo é caracterizado como uma pesquisa qualitativa de caráter descritivo e foi realizado em duas etapas com apoio em princípios da Fenomenologia. Na primeira etapa buscou conhecer a realidade considerada como "algo que emerge da intencionalidade 
da consciência voltada para o fenômeno" vivenciado pelas pessoas pesquisadas (Bicudo, Sposito, 1994). Nessa etapa foram entrevistados professores utilizando uma pergunta desencadeadora que solicitava que eles descrevessem como ensinam esporte na escola.

A realidade, na perspectiva fenomenológica, não é algo objetivo, mas é subjetiva e relativa uma vez que depende de um "estar-com-o-percebido", e é proveniente de percepções que ocorrem de maneira contextualizada, percepções que devem ser entendidas levando em consideração as situações que os sujeitos pesquisados vivenciam. A comunicação dessa realidade por meio da fala é a condição que nos permite pesquisa-la:

Sujeito e fenômeno estão no mundo-vida juntos com outros sujeitos, co-presenças que percebem fenômenos. A co-participação de sujeitos em experiências vividas em comum permite-lhes partilhar compreensões, interpretações, comunicações, desvendar discursos, estabelecendo a esfera da intersubjetividade (BICUDO, SPOSITO, 1994, p. 19).

Esses discursos foram transcritos, as unidades de significado identificadas (análise ideográfica) e suas respostas categorizadas para posterior análise (análise nomotética) e interpretação. Nessa modalidade de pesquisa, categorias são entendidas como "grandes regiões de generalidades compreendidas e interpretadas no âmbito do estudado" (HUSSERL, apud BICUDO, SPOSITO, 1994, p. 22).

O segundo momento da pesquisa constou da interpretação dos pesquisadores a respeito dos discursos analisados. Interpretar significa buscar compreender o fenômeno pesquisado e, para isso, o pesquisador se baseia nos significados expressados pelos pesquisados, mas não para por aí. O pesquisador vai além e busca em seus conhecimentos anteriores e até mesmo em sua história de vida os elementos que lhe permitirão construir um amplo quadro compreensivo a respeito do fenômeno estudado.

Segundo Fini (1994), uma vez cumprida a etapa descritiva da pesquisa, o pesquisador interpreta os discursos e, nesse momento, pratica a transcendência porque realiza uma reflexão sobre o significado do seu próprio discurso. Mesmo que a pesquisa fenomenológica não inicie lançando olhares teóricos ou conceituais pré-determinados ao fenômeno investigado, na etapa da interpretação

[...] o investigador não tem a pretensão de analisar o fenômeno como um expectador neutro, negando a experiência passada, em especial a experiência na sua área de estudos e de especialização (FINI, 1994, p. 53).

Para realizar a interpretação dos discursos, lançou-se mão da literatura, em especial do espectro de estilos de ensino de Muska Mosston para discutir aspectos das estratégias de ensino mencionadas no primeiro momento da pesquisa.

A Secretaria de Educação do município de Aparecida-SP autorizou o estudo e assinou o termo de autorização e responsabilidade. Os professores que aceitaram participar da pesquisa assinaram o termo de consentimento livre e esclarecido (TCLE) e o projeto de 
pesquisa foi aprovado pelo Comitê de Ética da Universidade São Judas Tadeu (USJT) sob registro: CAAE 39164314.9.0000.0089.

\section{Perfil dos sujeitos}

Os colaboradores desta pesquisa foram dez professores de EF escolar, sendo 7 do sexo masculino e 3 do sexo feminino. Dois docentes possuíam experiência de 1 a 5 anos com a EF escolar, 5 possuíam entre 6 a 10 anos de experiência, 2 possuíam de 11 a 15 anos e um professor possuía 20 anos de experiência na docência. Com relação ao vínculo empregatício, sete eram efetivos no cargo, e os demais eram contratados por meio de processo seletivo pelo período de um ano.

Em relação à formação inicial dos pesquisados, 7 professores possuem a licenciatura plena e 3 professores possuem a licenciatura e o bacharelado em EF, sendo que todos se formaram na mesma faculdade particular situada na região do Vale do Paraíba. Quanto ao ano de conclusão da graduação: 2 professores se formaram até o ano 1989, um no ano de 1998, 5 entre 2000 e 2009, e 2 terminaram a graduação de 2010 em diante.

Para análise das informações coletadas, os nomes dos professores foram omitidos e cada um deles será referenciado por um número.

No que se refere à formação continuada, o professor 1 possui especialização em EF escolar, o professor 3 possui especialização em Supervisão e Orientação educacional, o professor 7 tem especialização em Esporte para pessoas com deficiência, o professor 8 possui especialização em Ensino lúdico, e o professor 10 possui mestrado em Ciências Sociais.

\section{RESULTADOS E DISCUSSÃO}

As Matrizes 1 e 2 foram elaboradas após identificação das unidades de significados presentes nos discursos dos sujeitos pesquisados e nela constam as categorias elaboradas pelo pesquisador a partir das convergências das unidades de significado e que se referem às suas formas de ensinar. Essas matrizes constituem pontos de partida para discussão dos resultados da pesquisa.

Para discussão das estratégias de ensino que os professores de EF afirmam adotar lançaremos mão da literatura da área, com destaque para o Espectro de Estilos de Ensino de Muska Mosston. 
julho/2017

Matriz 1 - Dinâmica das atividades utilizadas para ensinar esportes

\begin{tabular}{|l|c|c|c|c|c|c|c|c|c|c|c|}
\hline $\begin{array}{l}\downarrow \text { Dinâmica das atividades/ } \\
\text { Sujeitos } \rightarrow\end{array}$ & P1 & P2 & P3 & P4 & P5 & P6 & P7 & P8 & P9 & P10 & Total \\
\hline Jogos pré - desportivos & $\mathrm{X}$ & & $\mathrm{X}$ & $\mathrm{X}$ & $\mathrm{X}$ & $\mathrm{X}$ & $\mathrm{X}$ & $\mathrm{X}$ & $\mathrm{X}$ & $\mathrm{X}$ & 9 \\
\hline $\begin{array}{l}\text { Jogos formais com as regras } \\
\text { oficiais }\end{array}$ & $\mathrm{X}$ & & $\mathrm{X}$ & $\mathrm{X}$ & $\mathrm{X}$ & $\mathrm{X}$ & $\mathrm{X}$ & $\mathrm{X}$ & $\mathrm{X}$ & $\mathrm{X}$ & 9 \\
\hline $\begin{array}{l}\text { Exercícios de repetição dos } \\
\text { movimentos }\end{array}$ & $\mathrm{X}$ & $\mathrm{X}$ & $\mathrm{X}$ & & $\mathrm{X}$ & $\mathrm{X}$ & $\mathrm{X}$ & & $\mathrm{X}$ & & 7 \\
\hline Atividades lúdicas & $\mathrm{X}$ & & $\mathrm{X}$ & $\mathrm{X}$ & & $\mathrm{X}$ & $\mathrm{X}$ & & $\mathrm{X}$ & & 6 \\
\hline Roda de conversa inicial & & $\mathrm{X}$ & & $\mathrm{X}$ & $\mathrm{X}$ & $\mathrm{X}$ & & $\mathrm{X}$ & & $\mathrm{X}$ & 6 \\
\hline Torneios internos & & $\mathrm{X}$ & & & $\mathrm{X}$ & $\mathrm{X}$ & & & $\mathrm{X}$ & $\mathrm{X}$ & 5 \\
\hline Trabalhos teóricos & $\mathrm{X}$ & & & & & $\mathrm{X}$ & & & $\mathrm{X}$ & $\mathrm{X}$ & 4 \\
\hline Roda de conversa final & & & & & & & & $\mathrm{X}$ & & $\mathrm{X}$ & 2 \\
\hline
\end{tabular}

Os docentes de EF da rede municipal de Aparecida-SP adotam como principais estratégias para ensinar esportes: os jogos pré-desportivos, os jogos formais com as regras oficiais e os exercícios de repetição de movimentos. Também aparecem nas respostas dos docentes a utilização de atividades lúdicas, roda de conversa inicial, realização de torneios internos, solicitar aos alunos que façam trabalhos teóricos sobre as modalidades esportivas.

Nove professores pesquisados relatam utilizar os jogos pré-desportivos para ensinar o esporte na escola como exemplificam as seguintes falas:

P1 - "Passo jogos pré-desportivos".

P3 - "depois vai para o jogo... tem sala que a gente faz adaptação".

P4 - “Em sequência o jogo adaptado ou recreativo e, por último, o jogo em si com regras oficiais".

P8 - "Às vezes eu faço o jogo sim, aliás na maioria das vezes eu faço. O jogo que seria próximo do real".

Os jogos pré-desportivos colaboram para o aprendizado das modalidades esportivas. Além disso, o professor consegue desenvolver uma função educativa na prática destes jogos, atrelando valores como a inclusão, a convivência, o respeito e a ética. O jogo pré-desportivo é imprevisível e possui desafios que motivam os alunos a participarem das aulas. Esses diferentes desafios (problemas) apresentados no jogo, fazem com que os alunos emitam respostas criativas e hábeis, individuais e coletivas que irão auxiliar tanto na melhora do jogo quanto na formação da sua vida (PAES; MONTAGNER e FERREIRA, 2009). 
Krug (2009) relata que, no campo da EF, os jogos pré-desportivos são riquíssimos em possibilidades para descobrir, planejar e inventar pois, dentro do jogo, sempre existe outra forma de passar a bola, ou uma estratégia para atacar ou defender no futebol, handebol ou basquetebol, dentre outras modalidades esportivas.

Desta forma, percebemos que os jogos pré-desportivos podem ter uma grande influência para a produção de novos conhecimentos ou de diferentes respostas para um problema, porém o professor precisa estar atento para intervir, mediar e propor novos problemas.

O jogo pré-desportivo é rico em situações problemas que podem estimular os alunos a pensarem em diferentes respostas, mas observou-se na presente pesquisa que os professores não relataram aplicar os jogos na escola com o objetivo de estimular os alunos a desenvolverem essas ações cognitivas e motoras dentro do jogo, visando a formação de alunos mais inteligentes taticamente e independentes para praticar os esportes ensinados. Os professores pesquisados parecem perceber a utilização do jogo pré-desportivo apenas como uma ferramenta para a melhora da execução dos gestos técnicos.

De acordo com eles, essas estratégias tem o objetivo maior de proporcionar um ambiente de aula lúdico, prazeroso e pouco formal. Os professores P1, P2, P3, P4, P6, P7 e P9 também fazem uso das atividades lúdicas para que seus alunos possam aprender o esporte de diferentes formas. As atividades lúdicas, presentes na cultura popular das crianças, podem ser utilizadas, porém, cabe ao professor adequá-las ao contexto das aulas para que atendam aos objetivos almejados, as características do grupo e possibilitem a vivência dos fundamentos de forma prazerosa, alegre e descontraída (PAES; MONTAGNER e FERREIRA, 2009).

Ensinar o esporte de maneira satisfatória está ligado à preparação dos alunos para executar as habilidades através da descoberta do prazer de realizar as atividades como também conscientizá-los sobre seus limites e capacidades possibilitando uma variedade de movimentos e novos conhecimentos. Dessa maneira, o professor deve centrar seu ensino nas questões pedagógicas que permeiam a aprendizagem de seus alunos, ou seja, inovando propostas, criando um ambiente participativo e saudável (NISTA- PICCOLO; TOLEDO, 2014).

Entretanto, a maioria dos docentes pesquisados utiliza o jogo formal como estratégia de ensino com todas as características do esporte de rendimento por acreditarem em uma maior efetividade dessa estratégia.

Finck (2012) relata que o esporte de rendimento possui objetivos e características que o distinguem do esporte educacional e do de lazer, pois o primeiro possui ênfase na competitividade, regras rígidas, movimentos padronizados, produtividade, o recorde e a vitória. Esse esporte é veiculado nas grandes mídias e influencia o ambiente escolar.

Esse modelo é o utilizado por nove entre dez professores pesquisados. Eles utilizam a estratégia do jogo formal com as regras oficiais para ensinar o esporte na escola. Isso foi evidente na fala dos professores. Entretanto, no ambiente escolar o professor deveria 
variar as formas de ensinar, pois apenas a prática esportiva por si não garante que os alunos aprendam as modalidades que estão sendo ensinadas e nem mesmo que sua formação em todas as dimensões do ser humano seja estimulada.

A estratégia de ensino que envolve o jogo formal com regras oficiais utilizada pelos professores está ligada ao modelo esportivista. De acordo com Merida e Merida (2013), as práticas esportivas ligadas a este modelo proporcionam apenas uma mera reprodução de movimentos e técnicas, sem que haja uma reflexão por parte de alunos e professores. Outro ponto negativo é a exclusão dos menos habilidosos, muitas vezes pelo próprio aluno que possui certa dificuldade e que não se sente à vontade para participar das aulas de caráter esportivo, ou até mesmo por colegas e professores que não reagem em situações colocadas pelo esporte tradicional no ambiente escolar como percebemos no relato:

P1 - "Existe aquela questão...a panelinha.... g gordinho vai para o gol...por mais que você trabalha isso sempre tem essa questão".

Os exercícios de repetição dos fundamentos fazem parte das estratégias de sete professores, os quais relatam a importância de aprender as técnicas esportivas para poderem vivenciar o esporte na escola:

P1 - " formação de base, os fundamentos é um trabalho que o atleta vai desenvolver ao longo do esporte que ele precisa praticar."

P2 - "você parte de um exercício com menor dificuldade até chegar no exercício complexo."

P3 - "Aí vai começar a prática dos fundamentos."

Em oposição aos modelos dominantes (tecnicista, esportivista e o biologicista), novas abordagens começam a surgir na década de 1970 com o intuito de trazer uma maior ação e reflexão para as aulas de EF e, com isso, tentar atender ao desenvolvimento das diferentes dimensões que constituem o ser humano.

No Brasil, algumas abordagens foram bem impactantes: a psicomotora, a construtivista, a desenvolvimentista e as abordagens críticas, que colaboraram para a ampliação das práticas pedagógicas educacionais e também da visão da área em relação aos possíveis conteúdos a ensinar (BRASIL, 1998).

Para Barroso e Darido (2006), o esporte como conteúdo da EF escolar possui muitas características que podem ser exploradas por professores e alunos. Diante disso, as aulas não devem ficar restritas aos movimentos e técnicas necessárias à prática esportiva e direcionarem um olhar diferenciado para os alunos mais habilidosos. É essencial ofertar condições de aprendizagem para todos os alunos, sejam quais forem suas diferenças físicas e motoras.

Castro, Giglio e Montagner (2008) apontam o jogo como uma ferramenta muito interessante para o aprendizado dos esportes coletivos, pois existem várias semelhanças 
funcionais, além de oferecer uma grande transferência do aprendizado para outras modalidades esportivas e para a própria modalidade objetivada.

Os jogos esportivos coletivos fazem parte da cultura do país e podem ser considerados um excelente meio para a formação dos cidadãos. Para isso, no entanto, a prática pedagógica deve ser realizada de forma criteriosa, sadia e com objetivos claros (PIMENTEL; GALATTI e PAES, 2010).

O profissional de EF tem que chamar a atenção dos alunos para as práticas esportivas por meio de recursos pedagógicos e estilos de ensino diferenciados que os motivem a participar das aulas de conteúdo esportivo (VENDITTI JÚNIOR; SOUZA, 2008).

Para utilizar estilos diferenciados, no entanto, é preciso conhece-los e estar disposto a aplica-los. Alguns autores se ocuparam em mostrar essa variedade de estilos de ensinar.

Gozzi, Ruete (2006) mostram que os estilos de ensino fazem parte de um spectrum que compõe uma teoria que objetiva analisar a estrutura das tomadas de decisões em situações de ensino e aprendizagem. Tais decisões podem ser tomadas tanto pelo professor, quanto pelo aprendiz-aluno. É importante ressaltar que o conhecimento do spectrum possibilita ao professor novos caminhos didáticos pelo conhecimento sobre a utilização de vários estilos de ensino. Tal conhecimento poderá auxiliar no planejamento e na condução das aulas, visando a que o educador se torne observador, conselheiro e um mediador que consiga colaborar para o desenvolvimento da autonomia de seus alunos.

O autor reconhecido a respeito do tema é Musska Mosston (*1925-+1994), um israelense que viveu na Rússia e, adulto, migrou para os Estados Unidos. Depois de chegar aos Estados Unidos, ensinou física, geometria, matemática, hebraico e EF. Ele via na EF oportunidades para o desenvolvimento físico, social, cognitivo, ético e emocional das crianças, o que o motivou a, em 1966, elaborar o spectrum de estilos de ensino com o objetivo de expandir as visões dos colegas de profissão sobre o tema.

O Espectro de Estilos de Ensino foi implementado em salas de aula públicas e privadas em todas as matérias, todos os graus, e com diferentes níveis de desempenho. O Espectro equipa os professores com o conhecimento fundamental para o desenvolvimento de um repertório de comportamentos profissionais que abraçam os objetivos necessários para se conectar e educar os alunos. (http://www.spectrumofteachingstyles.org/authors-muska.php).

O spectrum é composto por onze estilos de ensino, que representam possibilidade de estímulo ao desenvolvimento de capacidades básicas humanas: a capacidade de reprodução, a de produção e a de descoberta de novos conhecimentos.

Os estilos são organizados de acordo com essas capacidades: os estilos de Comando (A), Tarefa (B), Recíproco (C), Autoavaliação (D) e Inclusão (E) estão vinculados à reprodução, já os estilos Descoberta Guiada, (F) Descoberta Convergente ou Solução de Problemas Convergente (G), estão relacionados à descoberta e à produção de novos conhecimentos. Por fim, os estilos Descoberta Divergente ou Solução de Problemas Divergente $(\mathrm{H})$, Individual $(\mathrm{I})$, Iniciado pelo Aluno $(\mathrm{J})$ e Auto Ensino $(\mathrm{K})$ estão ligados à descoberta e à criatividade (GOZZI; RUETE, 2006). 
De acordo com Heine, Carbinatto e Nunomura (2009), o estilo de ensino Comando (A) é apontado como uma ferramenta importante para o ensino de habilidades motoras, pois possui algumas vantagens como: objetivos claros, a aquisição das habilidades é realizada de maneira específica, eficiência na organização do grupo e no tempo de execução das atividades. Neste estilo, os alunos sentem-se seguros por saber o que, e como irão desempenhar as atividades. Nele, o professor determina tudo, ou seja, o volume, o ritmo, a intensidade e, por assim proceder, não abre espaço para a criatividade individual e desenvolvimento da autonomia dos alunos.

No estilo Tarefa (B) é esperado que os alunos executem uma determinada atividade conforme um modelo, mas existe a possibilidade de que eles tomem decisões relacionadas ao domínio físico, ordem das tarefas, tempo de início, velocidade e ritmo de execução, dentre outros (GOZZI; RUETE, 2006). Este estilo está ligado à situação pedagógica na qual o professor apresenta uma tarefa à turma, que pode ser realizada de acordo com o padrão de desempenho de cada aluno, ou seja, o aluno conhece seus limites, pode escolher o número de vezes, a duração e intensidade que conseguir superar, respeitando a sua individualidade (HEINE; CARBINATTO; NUNOMURA, 2009).

Krug (2009) afirma que a interação social entre os pares e os possíveis feedbacks proporcionados pelo par, sob supervisão do docente, estão relacionados ao estilo Recíproco (C). Neste estilo, o retorno dado pelo par está embasado em uma ficha construída pelo professor, que os auxiliará na execução e na observação das tarefas.

De acordo com Gozzi e Ruete (2006), no estilo Autoavaliação (D) a retroalimentação deixa de ser dada pelo professor ou por outro aluno e passa a ser responsabilidade do próprio aluno, buscando que este tenha maior poder de decisão.

No que se refere ao estilo Inclusão (E), pode-se dizer que são planejados vários níveis de dificuldade nas tarefas com a intenção de incluir todos os alunos, ou seja, ao explicar a atividade, o professor comentará sobre as opções possíveis. Isso permite ao aluno fazer uma reflexão e escolher o desafio adequado à suas características. Dessa maneira, o aluno aprende a avaliar as opções e, quando se considerar pronto, pode partir para o nível de exigência subsequente (KRUG, 2009).

Com relação à descoberta e à produção de novos conhecimentos existem diferentes estilos. Gozzi e Ruete (2006) relatam que o estilo Descoberta Guiada (F) é caracterizado pela relação particular entre professor e aluno, sendo que os inúmeros questionamentos do professor gerarão uma sequência de respostas dadas pelo aprendiz, ainda que cada pergunta leve a apenas uma resposta, sendo um processo que converge para a descoberta de um conceito planejado.

No estilo de Descoberta Convergente ou Solução de Problemas Convergente (G), o aluno é estimulado a utilizar o seu raciocínio, pensamento crítico, ensaio e erro, com o intuito de descobrir uma única resposta para a questão ou apenas uma solução para o problema (KRUG, 2009).

O estilo de Descoberta Divergente ou Solução de Problemas Divergente $(\mathrm{H})$ é caracterizado pela busca de múltiplas e divergentes respostas, fazendo com que o aluno entenda a estrutura da atividade e, com criatividade, consiga verificar e encontrar inúmeras soluções para determinado problema (GOZZI; RUETE, 2006). 
A respeito do estilo Programa Individual (I), Krug (2009) o define como um momento de maior independência para descobrir a solução para o problema do aluno, sendo que o papel do professor consiste nas decisões sobre o conteúdo geral a ser apresentado, enquanto o papel do aluno é executar um tópico específico deste conteúdo geral, ou seja, identificar e analisar situações para a solução deste desafio, além de planejar o desempenho nas ações.

Já o estilo Iniciado pelo aluno (J) está ligado à condição do ensino e da aprendizagem pelo próprio aluno, enquanto o estilo Auto Ensino $(\mathrm{K})$ dispensa a presença do professor, pois o objetivo é ensinar a si mesmo (GOZZI; RUETE, 2006).

Os docentes de EF pesquisados utilizam apenas os estilos Comando (A), onde o professor tem o controle de tudo, ou seja, toma as decisões em todos os momentos da aula e resta ao aluno apenas executar e obedecer ao professor, tendo sempre um modelo a seguir. Utilizam também o estilo Tarefa (B), onde algumas decisões são transferidas ao aluno, propondo uma nova realidade entre professor e aluno, já que o professor passa a confiar que o aluno poderá tomar algumas decisões na execução da tarefa, mas deve ainda seguir as orientações estabelecidas pelo professor.

Nesses estilos, o aluno é apenas um ouvinte e reprodutor dos movimentos, tomando poucas decisões nas tarefas, como exemplificam os seguintes relatos:

P6 -"Vamos treinar fundamentos de novo? Vamos. Vamos melhorar isso. Vamos fazer isso tudo são detalhezinhos que vão fazer a diferença, essa coisa de brilhar mesmo, do lapidar, da própria situação, até mesmo a situação de um atleta".

P8 - "Eu começo com os fundamentos básicos que seria, vamos dar um exemplo: basquete começo lá: Olha gente fundamento do passe, existem vários tipos de passes: passe de peito, passe picado, passe de ombro e vou indo.... Vou modificando, depois dou arremesso, ensino certos arremessos, adentrar nas regras mesmo da modalidade eu acho que é isso".

Os estilos Recíproco (C), Autoavaliação (D) e Inclusão (E) não fazem parte do repertório de estratégias dos professores pesquuisados, apesar de estarem ligados à repetição e execução de tarefas. Eles possuem algumas características específicas que não são mencionadas pelos professores na descrição de suas atividades. Ressaltamos, ainda, que nenhum dos docentes mencionou utilizar estratégias de ensino que remetessem aos estilos de ensino relacionados com a produção de novos conhecimentos.

Para Heine, Carbinatto e Nunomura (2009), o aluno que aprende um esporte exclusivamente por meio do estilo Comando (A) alcançará uma melhora dos aspectos motores e físicos, pois este estilo estimula em grande escala estes aspectos, porém desenvolverá em menor escala o aspecto cognitivo. Com isso, ficará bastante dependente da voz ou sinais de comando do professor, o que contribui pouco para desenvolver a autonomia, a iniciativa e a capacidade de tomar decisões.

Gozzi e Ruete (2006) afirmam que no estilo Tarefa (B) há uma grande semelhança com o Comando (A), pois os alunos ainda seguem um modelo estabelecido pelo professor, porém existe a possibilidade de os alunos tomarem algumas decisões, relacionadas ao 
aspecto físico-motor, sendo elas: a ordem das tarefas, o tempo de início, a velocidade e o ritmo para a execução, o término da tarefa, o intervalo, a postura, o local.

De acordo com a pesquisa de Gozzi e Ruete (2006), em segmentos não escolares (clubes) foram encontrados alguns resultados que se relacionam com os nossos sobre os estilos de ensino. Em aulas de natação analisadas predominavam, com 46\%, o estilo Tarefa, seguido pela Descoberta Guiada - 23\%, estilo Inclusão - 15\%, Autochecagem e Produção Divergente com $8 \%$. Na modalidade esportiva futebol foi encontrado $55 \%$ para o estilo Tarefa e $43 \%$ para estilo Comando.

Na pesquisa de Silva (2013), realizada em seis escolas com seis professores de EF que atuavam no Ensino Fundamental I, foram observadas 12 aulas de cada professor, totalizando 72 aulas e em todas as aulas o estilo Tarefa (B) prevaleceu como principal estratégia de ensino.

Os docentes mencionaram que utilizam a roda de conversa para iniciar as aulas. Nesse momento, os professores explicarão os objetivos das aulas e as possíveis atividades que serão realizadas, atentando e motivando os alunos para participação nas atividades. Esse é um momento necessário para que os alunos se envolvam e até mesmo participem questionando e dialogando com o professor de EF.

Para Mosston e Ashworth (1986), a roda de conversa inicial faz parte da fase de pré-impacto, na qual o professor explica e demonstra as tarefas e os modelos que os alunos seguirão na aula. É considerado um momento no qual constantes orientações acontecerão para o melhor desenvolvimento das atividades.

Rodrigues e Darido (2012) recomendam que as aulas iniciem e finalizem em roda, de modo que todos os alunos possam se posicionar, lembrando e debatendo sobre o que foi realizado na presente aula e na anterior, além disso, permite trazer fatos novos ou curiosidades acerca do cotidiano esportivo, no entanto, nem todos os professores pesquisados faziam as rodas de conversa iniciais.

Percebemos a importância tanto da roda de conversa no início quanto ao final da aula, pois são momentos nos quais alunos e professores podem dialogar e debater. Na presente pesquisa, apenas os professores P8 e P10 disseram realizar uma roda de conversa final com o objetivo de fazer um resumo geral da aula, possibilitar a discussão dos alunos, além de fornecer feedbacks para os alunos sobre o processo de ensino e aprendizagem. Podemos observar essa realidade nos discursos abaixo:

P8 - "Eu começo lá na parte inicial que seria introdução, aí a gente vai para um alongamento, fazer um aquecimento e falar de algum jogo, a aula é sempre dobradinha. Aí depois eu entro na parte específica que é a parte dos fundamentos ou das regras. Depois a gente faz o jogo mesmo e para finalizar a gente termina: Olha gente o que foi passado hoje? E se sobrar um tempinho ou outro eles ficam um tempinho livres".

P10 - "A quinta parte seria uma roda de conversa, que eles chamam de volta à calma, roda de conversa para poder discutir a aula: o que achou, a maior dificuldade, a experiência vivida. Tudo isso com o intuito do aluno reflexivo sobre sua própria prática". 
Nesse sentido, na roda de conversa final o professor pode propor aos alunos discutir os pontos positivos e negativos, os aprendizados, o que faltou e o que será desenvolvido na próxima aula, além de outros aspectos que o professor julgar necessário. Na roda, todos são iguais, não existem melhores ou piores, todos podem se ver, ouvir e falar, ou seja, um espaço coletivo que propicia aprendizados importantes como ouvir o colega, aguardar a sua vez para falar, respeitar opiniões, argumentar, discordar e concordar (RODRIGUES; DARIDO, 2012).

Nos estilos de ensino propostos por Mosston, os feedbacks são fundamentais para o processo de aprendizado dos alunos. Dependendo do estilo, tais feedbacks podem ser dados pelos próprios alunos a outros, ou do professor aos alunos. Sendo assim, orientações são feitas aos alunos durante a execução das atividades, já na fase pós-impacto mais informações e devolutivas serão comentadas. (KRUG, 2009).

Outro ponto importante a ser discutido sobre as estratégias de ensino utilizadas é o fato de a Secretaria de Educação do município pesquisado organizar as aulas de EF no contraturno e com turmas segregadas por gênero. Essa forma de organização é um fato preocupante, pois os alunos necessitam deste convívio social intergêneros para auxiliar na sua formação. Na percepção de 5 professores (P1, P2, P3, P4 e P5), essa separação de gêneros é essencial, pois as práticas esportivas são melhor desenvolvidas.

P2 - "Bom, turmas mistas é complicado. E eles já fazem junto do primeiro ao quinto ano, então do sexto ao nono, separado fica melhor".

P3 - "Desse modo eu acho positivo porque acaba trabalhando uma... vamos supor, uma dessa específica as meninas uma ginástica e com os meninos não. Eles não irão aceitar isso. Acaba atrapalhando. Nesta específico de separar, eu acho positivo".

P4 - "Eu acho que o horário do contra turno é um horário ideal. Sou a favor do horário de contra turno. Primeiramente pelo fato dos alunos que vem no contra turno são os alunos que estão interessados em fazer a aula. Fico dividido. Eu acho válido a separação de masculino e feminino, mas por outro lado eu acho que ficou um pouco a desejar também, tendo em vista que, quando as duas turmas, turmas mistas, masculina e feminina estão presentes existe uma série de dificuldades, principalmente com a parte do desempenho das meninas, crítica por parte dos meninos, deboche, brincadeiras, coisas, comportamento e atitudes dos meninos que podem constranger as meninas. Além do fator sexualidade. Já percebo que está muito acentuado nas duas turmas o que se não houver o devido controle acaba virando uma bagunça".

Podemos perceber que estes professores seguem e concordam com uma estrutura didática que separa meninos e meninas das aulas e propõe um modelo do esporte de alto rendimento para as aulas de EF na escola, como seguem, também, as orientações curriculares da rede. Em resumo, a perspectiva educacional destes docentes não se vincula a orientações propostas pela literatura pedagógica mais recente no que se refere à coeducação. 
Para Galvão, Rodrigues e Silva (2005), o esporte é uma manifestação da cultura corporal de movimento e, para ensiná-lo na escola, as estratégias de ensino precisam ser variadas, tendo um tratamento diferenciado. Sendo assim, ao ensinar uma modalidade esportiva nas aulas de EF, os autores sugerem que os docentes devem refletir com os discentes sobre o difícil relacionamento entre meninos e meninas na realização da prática esportiva, a exclusão dos menos habilidosos, a violência, as dificuldades relacionadas ao entendimento sobre a necessidade e os mecanismos de construção das regras, a aplicação das noções sobre a organização tática.

Os professores também podem propor jogos nos quais as diferenças de habilidades entre meninos e meninas, como no chutar, por exemplo, não sejam tão marcantes, construindo um ambiente mais harmônico durante as aulas. Utilizar materiais alternativos como balões, bolas de espuma, bolas de meia com enchimento macio, por exemplo, como alternativa aos oficiais também pode gerar bons resultados e estimular a participação dos menos habilidosos (GALVÃO; RODRIGUES; SILVA, 2005).

Ainda é necessário que os professores de EF trabalhem no sentido de incluir todos os alunos nas aulas, trabalhem de forma interdisciplinar, respeitem o projeto político pedagógico da escola, incentivem o trabalho com notícias sobre anabolizantes, violência no esporte, padrão de beleza, etc, utilizem vídeos, coletem informações na internet e na mídia impressa, estimulem a autonomia dos alunos, diversifiquem os espaços e os materiais, convidem especialistas nas modalidades esportivas ensinadas para realizar palestras, trabalhem com turmas heterogêneas, realizem trabalho em grupo e discutam as relações de gênero presentes nos esportes (DARIDO; SOUZA JÚNIOR, 2013).

Neira (2014) sugere que o professor deve permanecer atento às relações embutidas na trajetória e organização da modalidade esportiva ensinada, procurando ajudar o grupo a significá-las. O professor pode indagar sobre as condições assimétricas de participação dos sujeitos, questões de gênero, consumo, história, formas de organização da prática, gestos e recursos empregados, entre outros aspectos. Nessa perspectiva, é importante que as atividades de ensino priorizem o diálogo sobre os diversos significados apreendidos durante a leitura da gestualidade que caracteriza um determinado esporte.

Maldonado, Silva e Neira (2015) mencionam que as propostas curriculares estaduais brasileiras de EF sugerem que os professores que ensinam esportes coletivos devem promover debates entre os alunos, ministrar atividades práticas, utilizar recursos audiovisuais, vivenciar os esportes coletivos, realizar apresentações dos conteúdos desenvolvidos, realizar pesquisas em grupo ou de forma individual, entrevistar pessoas envolvidas com os esportes coletivos, elaborar painéis com ideias relacionadas aos esportes coletivos, praticar o esporte coletivo compreendendo os elementos técnicos e táticos em conjunto, propor a realização da auto avaliação, realizar rodas de conversa e utilizar a ludicidade para ensinar os esportes coletivos.

Fica claro, portanto, que existe uma gama de possibilidades de utilizar o esporte como meio educativo e que parece ser pouco utilizada pelos professores pesquisados.

Dentre as técnicas de ensino utilizadas pelos professores, constam as técnicas expositivas que analisaremos a seguir, a partir da Matriz 2. 
Matriz 2 - Técnicas expositivas utilizadas para ensinar esportes

\begin{tabular}{|l|c|c|c|c|c|c|c|c|c|c|c|}
\hline$\downarrow$ Técnicas expositivas / Sujeitos $\rightarrow$ & P1 & P2 & P3 & P4 & P5 & P6 & P7 & P8 & P9 & P10 & Total \\
\hline Demonstrações dos fundamentos & & & $X$ & & X & X & & & & $X$ & 4 \\
\hline Explicações durante as atividades & $X$ & & & & & $X$ & & & $X$ & $X$ & 4 \\
\hline Recursos audiovisuais & $X$ & & $X$ & & & $X$ & $X$ & & & & 4 \\
\hline $\begin{array}{l}\text { Apresentação dos materiais e } \\
\text { equipamentos esportivos }\end{array}$ & & & $X$ & & & & $X$ & $X$ & & & 2 \\
\hline
\end{tabular}

Nista-Piccolo e Moreira (2012) defendem que o professor tem um papel essencial na formação de seus alunos. Ele tem o dever de ser um facilitador e um mediador do conhecimento, pois, é ele quem elabora o ambiente pedagógico, cria as situações didáticas, estabelece metas e objetivos, seleciona os conteúdos a serem desenvolvidos nas aulas de EF.

Apesar de a demonstração ser um ponto importante no aprendizado do esporte na EF escolar, apenas os professores P3, P5, P6 e P10 mencionaram utilizar essa técnica.

P3 - "Explico. Às vezes até demonstro. Levo uma bola para sala e às vezes até demonstro".

P 5 - "E aí ensino por exemplo: fundamento toque. Aí mostro na bola, posição. Depois começa o 2 a 2. E aí toca, segura, o outro, toca. É difícil né. Depois manchete. A mesma coisa. Ensino posicionamento de braço, depois começa uma passada da cortada, como impulso, saque. Todo processo do fundamento".

P6 - "Porque tem aluno que aprende ali fazendo, outros ouvindo, outros vendo".

P10 - "Aí você tem descrição de movimento explicando o que que é realizado, mas principalmente dentro do próprio jogo."

A demonstração dos movimentos e técnicas pelos professores de EF, para Krug (2009) está relacionada ao estilo Comando (A) que permite demonstrar a tarefa estabelecendo o modelo a ser copiado. Esse estilo visa o aprendizado e a memorização de padrões ou habilidades estereotipadas. Contudo, a demonstração dos movimentos e tarefas pode ser utilizada em outros estilos de ensino e ser aproveitada de outra forma para estimular a crítica e a criatividade, por exemplo.

Outro ponto importante é a observação e a retroalimentação feita pelo professor, que poderá orientar antes, durante e ao fim da execução das tarefas.

Alguns professores pesquisados destacam a importância das pausas para explicações das atividades. Esse aspecto é necessário, pois o profissional pode colaborar para que os alunos consigam entender melhor seus erros e acertos.

Durante as aulas é interessante garantir a participação efetiva dos alunos em todas as atividades, buscar sempre seu envolvimento, por exemplo: se em um jogo uma equipe 
está perdendo por alguns pontos, é necessário que o professor faça uma intervenção e uma reflexão com o grupo, solicitando que esta equipe, que está em desvantagem, pense em algumas estratégias defensivas para evitar levar outros pontos, incentivando que os alunos participem e proponham soluções para o problema encontrado no jogo (RODRIGUES; DARIDO, 2012).

Sendo assim, o profissional deve intervir nas atividades com o objetivo de indagar e motivar os alunos a buscarem outras respostas para os problemas ou dificuldades na execução das atividades. Nos discursos dos professores pesquisados, fica evidente que as pausas possuem outras características e finalidades e estão ligadas à obediência às regras oficiais da modalidade esportiva:

P1 - "Do $6^{\circ}$ ao $9^{\circ}$ ano a gente sempre deixar jogar mais. Daí apita, para. Não. Olha, o jogo não é para fazer isso".

P9 - "E durante as aulas vou explicando a parte teórica: lateral, pé na linha, a área só do goleiro".

O estilo Descoberta Guiada (F) é uma boa estratégia para instigar os alunos a descobrirem a resposta de um problema, como, por exemplo, em um jogo de alvo realizado com as mãos, os jogadores precisam passar a bola entre eles, porém existe uma marcação intensa por parte da outra equipe, sendo assim é necessário utilizar diferentes tipos de trajetórias do passe para que a bola chegue até o companheiro. O professor pode fazer pausas durante o jogo e estabelecer uma pergunta que encaminhe o aluno a responder o problema, que, no caso, seria passar a bola para o companheiro que está marcado.

No entanto, como percebemos na presente pesquisa, o simples fato de parar a aula, um exercício, ou jogo e apenas advertir sobre as regras e até mesmo corrigir os movimentos, não é suficiente para reforçar, por exemplo, uma educação democrática que visa a participação e a autonomia, pois é interessante que haja um diálogo no qual o aluno tenha oportunidade de se envolver ativamente.

Alguns professores mencionaram utilizar a mídia ou vídeos no interior da escola para estimular o aprendizado.

P1 - "Olha vai passar um jogo de handebol feminino na Globo. Assistam para vocês verem e depois a gente conversa".

P3 - "Escola que tem condições eu passo um vídeo, a que não tem, a gente não faz".

P6 - "Vai ter os Jogos Pan-americanos, assistam. Esse bimestre é handebol, assistam".

Neira (2014) recomenda que as crianças e adolescentes devem ser tratadas como leitoras e produtoras das práticas esportivas para que alcancem uma compreensão melhor dos seus significados. Ao propor como exemplo a analisar o skate, o autor explicita que 
os professores de EF podem discutir sobre as técnicas empregadas pelos skatistas, suas vestimentas, gírias e regulamentos das competições. Para que isso aconteça, o docente pode organizar vivências, alternando executores e observadores, apresentar vídeos, coletar relatos de skatistas, entre outras atividades.

Os professores P7 e P8 relatam que, ao iniciarem o ensino de modalidade esportiva nas aulas, apresentam aos alunos as bolas, a quadra e outros materiais necessários à prática esportiva.

P7 - "depois num segundo momento a parte de ilustração que seria de livro, que seria mostrar como se faz, como é a quadra, as medidas por exemplo, o basquetebol na medida...".

P8 - "primeiro mostro material para eles e vou passando para eles poderem ver de mão em mão."

Portanto, em relação às estratégias de ensino para ensinar esportes, os professores de EF da rede municipal de Aparecida, em muitos momentos, não seguem as indicações realizadas pela literatura mais recente da área, pois utilizam como principais estratégias didáticas os tradicionais jogos pré-desportivos, jogos formais com regras oficiais, exercícios com repetições de movimentos, a realização de torneios internos, demonstração dos fundamentos, apresentação dos materiais e equipamentos esportivos, explicação e intervenção durante as atividades, deixando claro o seu enfoque nos conteúdos de ordem procedimental e o estímulo à prática de poucas modalidades esportivas apenas pelos alunos mais habilidosos.

Embora também apareçam nas estratégias dos docentes a utilização de atividades lúdicas, a roda de conversa inicial, trabalhos teóricos e roda de conversa final, essas estratégias estão sempre voltadas para o ensino das técnicas e das regras das modalidades esportivas e para a melhora do comportamento dos alunos para que possam praticar os esportes ensinados e não direcionadas à formação do pensamento crítico e da cidadania dos discentes.

\section{CONSIDERAÇÕES FINAIS}

As estratégias utilizadas pelos docentes são predominantemente ligadas ao estilo Comando (A) e Tarefa (B), pois os professores, a todo o momento, estão à frente das ações nas aulas e controlam a organização, o tempo destinado à tarefa, e na maioria das vezes buscam desenvolver as habilidades motoras dos alunos e não possibilitam uma maior participação e envolvimento dos alunos nas aulas. Os alunos, por sua vez, são meros reprodutores das atividades propostas pelos docentes, não possuem espaço para comentar, dialogar ou interferir, pontos tidos como muito importantes para uma educação autônoma e democrática. 
julho/2017

De uma maneira geral, esses resultados confirmam os apresentados em outras pesquisas sobre o mesmo tema. O que nos surpreende, entretanto, é a falta de mudanças didático-pedagógicas na cidade pesquisada tendo em vista que a produção de literatura em defesa de métodos mais participativos, democráticos, criativos, já é bastante extensa e difundida na área.

Como todos os professores foram graduados na mesma Instituição de Ensino Superior, a importância da formação continuada para mudar o quadro observado vê-se ampliada. No entanto, parece que os gestores responsáveis pela oferta de formação continuada aos professores de EF da região desconhecem ou desvalorizam essas possibilidades didático-pedagógicas que a literatura já vem apontando há mais de uma década.

Essa pesquisa foi um primeiro movimento de aproximação destes professores e se limitou a identificar e analisar o que disseram a respeito de como ensinam esporte na escola. No entanto, novas pesquisas precisam ser feitas para melhor compreender as razões pelas quais os professores não se sensibilizam com novas propostas didáticas ou por que seu ideário sócio-político-pedagógico não se coaduna com elas.

\section{REFERÊNCIAS}

BARROSO, A. L. R.; DARIDO, S. C. Escola, Educação Física e esporte: possibilidades pedagógicas. Revista Brasileira de Educação Física, Esporte, Lazer e Dança, Rio Claro, v. 1, n. 4, p. 101-114, 2006.

BICUDO, M. A. V.; SPOSITO, V. H. C. Pesquisa Qualitativa em Educação, Piracicaba, Unimep, 1994.

BRASIL. Secretaria de Educação Fundamental. Parâmetros Curriculares Nacionais: Educação Física / Secretaria de Educação Fundamental. - Brasília: MEC/SEF, 1998.

CASTRO, J. A. D.; GIGLIO, S. S.; MONTAGNER, P. C. O jogo no ensino do handebol: proposta de um plano de ensino pensado para a prática diária. Motriz, Rio Claro , v. 16, n. 1, p. 67-73, 2008.

CORREIA, M. M. Jogos cooperativos perspectivas, possibilidades e desafios na Educação Física Escolar. Revista Brasileira de Ciências do Esporte, Campinas, v. 27, n. 2, p. 149-164, 2006.

DARIDO, S. C.; SOUZA JÚNIOR, O. M. Para ensinar Educação Física: possibilidades de intervenção na escola. 7. ed. Campinas, SP: Papirus, 2013.

FINCK, S. C. M. A Educação Física e o esporte na escola: cotidiano, saberes e formção. Curitiba: Itersaberes Dialógica, 2012.

FINI, L. D. T. A situacionalidade de Psicologia Educacional - Adolescência nos cursos de Licenciatura da Unicamp. In: BICUDO, M. A. V.; SPOSITO, V. H. C. Pesquisa Qualitativa em Educação, Piracicaba, Unimep, 1994a.

GALVÃO, Z.; RODRIGUES, L. H.; SILVA, E. V. M. E. Esporte. In: DARIDO, S. C.; RANGEL, I. C. A. Educação Física na Escola: implicações na prática pedagógica. Rio de Janeiro: Guanabara Koogan, 2005. 
GOZZI, M. C. T.; RUETE, H. M. identificando estilos de ensino em aulas de educação fisica. Revista Mackenzie de Educação Física e Esporte, São Paulo, n. 1, p. 117-134, 2006. GUIMARÃES, A. A.;. PELLINI F. C.; ARAUJO J. S. R.; MAZZINI J. M. Educação Física Escolar: atitudes e valores. Motriz, Rio Claro, n. 1, v. 7, p. 17-22, 2001.

HEINE, V.; CARBINATTO, M. V.; NUNOMURA, M. Estilos de ensino e a iniciação da capoeira para crianças de 7 a 10 anos de idade. Pensar a Prática, Goiânia, v. 12, n. 1, p. 1-12, 2009.

KRUG, D. F. Metodologia do Ensino da Educação Física: O Spectrum de Estilos deMuska Mosston e Uma Nova.Visão! 1 ${ }^{\text {a }}$. ed. Curitiba: JM Editora, 2009.

MALDONADO, D. T.; SILVA, S. A. P. S.; NEIRA, M. G. O trabalho pedagógico com os esportes coletivos nas propostas curriculares brasileiras para o ensino médio. Revista Brasileira de Educação Física Escolar, São Paulo, ano 1, v. 2, p. 61-73, 2015.

MERIDA F. V.; MERIDA M. Abordagem esportivista. In: SILVA, S. A. P. S. Portas abertas para a Educação Física: falando sobre abordagens pedagógicas. São Paulo: Phorte, 2013. MOSSTON M.; ASHWORTH S. La enseñanza de la educación fisica: la reforma de los estilos de enseñanza. Barcelona: Editorial Hispano Europea, 1986.

NEIRA, M. G. Práticas Corporais: brincadeiras, danças, lutas, esportes e ginásticas. São Paulo: Melhoramentos, 2014.

NISTA-PICCOLO, V. L.; MOREIRA, W. W. Esporte como conhecimento e prática dos anos iniciais do ensino fundamental. São Paulo: Cortez, 2012.

NISTA-PICCOLO, V.; TOLEDO, E. D. Abordagens pedagógicas do esporte: modalidades convencionais e não convencionais. Campinas: Papirus, 2014.

PAES, R. R.; MONTAGNER, P. C.; FERREIRA, H. B.; Pedagogia do Basquetebol: Iniciação e Treinamento em Basquetebol. Rio de Janeiro: Guanabara Koogan, 2009.

PIMENTEL, R. M.; GALATTI, L. R.; PAES, R. R. Pedagogia do esporte e iniciação esportiva tardia: perspectivas a partir da modalidade basquetebol.. Pensar a Prática, Goiânia, v. 13, n.1, p. 1-15, 2010.

RODRIGUES H. A.; DARIDO S. C. Basquetebol na escola: uma proposta didáticopedagógica. Rio de Janeiro: editora Guanabara Koogan, 2012.

SILVA, J. V. P.; Prática pedagógica em Educação Física nos anos iniciais do Ensino Fundamental. Pensar a Prática, Goiânia, v. 16, n. 1, p. 148-163, 2013.

Spectrum Institute for Teaching and Learning. Musska Mosston, Disponível em: < http:// www.spectrumofteachingstyles.org/authors-muska.php>. Acesso em 29 nov 2016.

VENDITTI JÚNIOR R.; SOUSA, M. A. Tornando o "jogo possível": reflexões sobre a pedagogia do esporte, os fundamentos dos jogos desportivos coletivos e a aprendizagem esportiva. Pensar a Prática. Goiânia: v. 11, n. 1, p. 47-58, 2008.

Recebido em: setembro/2016 Aprovado em: janeiro/2017 